but recent registry data point to better responses and retention if a drug with a different mode of action is prescribed.

Objectives: Assess the long-term retention of rituximab (RTX) and TNFi following first biologic (b)DMARD inadequate response in RHUMADATA ${ }^{\circledR}$ registry patients (pts) with RA

Methods: Data from RHUMADATA ${ }^{\circledR}$ pts with RA prescribed either RTX or TNFi as the second bDMARD after 1 January 2006 were analysed. Pts were followed until treatment discontinuation or 9 January 2017 cut-off. Pt characteristics were compared using descriptive statistics, bDMARD discontinuation rates using Kaplan-Meier methods, and proportional hazard models were used to identify predictors of treatment discontinuation.

Results: Data for 53 and 194 pts prescribed RTX or a TNFi, respectively, as second-line treatment were extracted. No clinically significant differences in baseline characteristics were noted between treatment groups. Most pts were women (74.9\%), average age (SD) was 45.2 (12.9) years at diagnosis and disease duration 10.5 (8.7) years. Most pts were stopping an anti-TNF agent: $100 \%$ of those who were switched to RTX and $83 \%$ of those who were prescribed a second anti-TNF. Overall, $77.3 \%$ of pts stopped their first bDMARD after $>6$ months of treatment (secondary failure). Significant differences in retention between RTX and TNFi groups (log-rank $\mathrm{p} \leq .0001$ ) were observed (Table, Figure). Results remained unchanged for pts treated with TNFi only in first line, and primary/secondary failure of the first bDMARD did not affect sustainability of the second agent. Lack of efficacy (54.4\%) and AEs (16.5\%) were the most commonly cited reasons for treatment discontinuation.

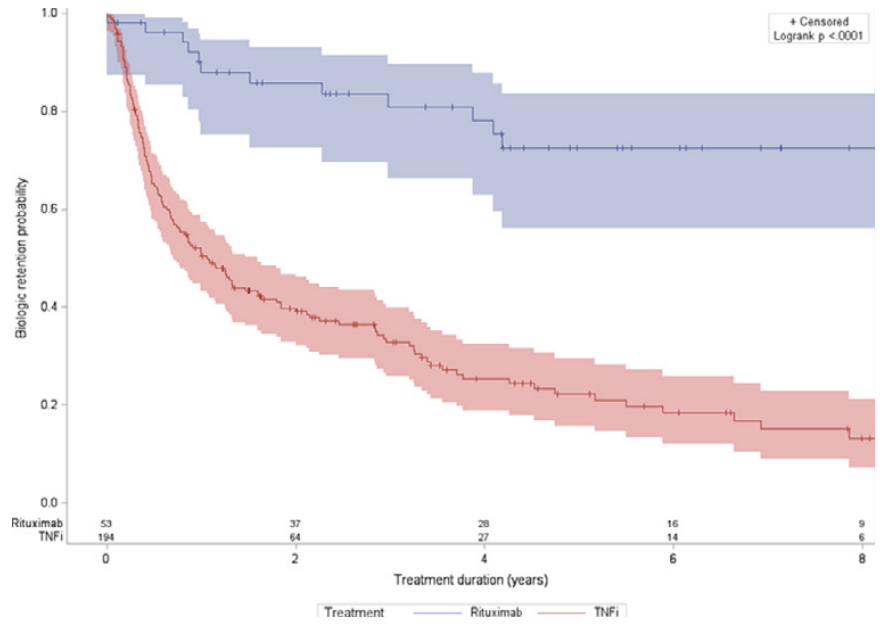

Conclusions: Rituximab has better sustainability over a second line TNFi in RA patients having failed one prior bDMARD.

Disclosure of Interest: D. Choquette Grant/research support from: Roche, Consultant for: Roche, L. Bessette Grant/research support from: Amgen, BMS, Janssen, Roche, UCB, AbbVie, Pfizer, Merck, Celgene, Sanofi, Lilly, Novartis, Consultant for: BMS, Janssen, Roche, UCB, AbbVie, Pfizer, Celgene, Lilly, Novartis, B. Haraoui Grant/research support from: BMS, Janssen, Roche, Consultant for: Abbvie, Amgen, BMS, Celgene, Janssen, Merck, Pfizer, Roche, Sandoz, UCB, Speakers bureau: Pfizer, UCB, F. Massicotte: None declared, J.-P. Pelletier: None declared, J.-P. Raynauld Speakers bureau: AbbVie, Amgen, BMS, Janssen, Pfizer, Roche, Sanofi, Novartis, UCB, M.-A. Rémillard: None declared, D. Sauvageau: None declared, A. Turcotte Consultant for: Amgen, Abbvie, BMS, Celegene, Janssen, Roche, Pfizer, Lilly, Novartis, Merck, Sanofi, UCB, Speakers bureau: Amgen, Abbvie, BMS, Celegene, Janssen, Roche, Pfizer, Lilly, Novartis, Merck, É. Villeneuve Consultant for: Celgene, Cimzia, Pfizer, Speakers bureau: Abbvie, Roche, BMS, L. Coupal: None declared

DOI: 10.1136/annrheumdis-2017-eular.6361

\section{SAT0196 REPEATED RITUXIMAB INFUSIONS FOR THE THERAPY OF RHEUMATOID ARTHRITIS IS NOT ASSOCIATED WITH INCREASED RATES OF SERIOUS INFECTIONS}

D.A. Pappas $^{1,2}$, G.W. Reed ${ }^{2,3}$, S. Zlotnick ${ }^{4}$, J. Best ${ }^{4}$, R. Magner ${ }^{3}$, G. Persuitte $^{2}$, J. Greenberg 2,5 . ' Columbia University, New York, NY; ${ }^{2}$ Corrona, LLC, Southborough, MA; ${ }^{3}$ University of Massachusetts Medical School, Worcester, $M A ;{ }^{4}$ Genentech, Inc., South San Francisco, CA; ${ }^{5}$ New York University School of Medicine, New York, NY, United States

Background: Extended observations in clinical trials have not demonstrated an increased risk of serious infection events (SIE) in patients with rheumatoid arthritis (RA) treated with rituximab. ${ }^{1}$ However, continuous surveillance using large-scale observational data is of importance.

Objectives: To evaluate the rate of SIEs among patients with RA who received only an initial rituximab infusion vs those retreated with $\geq 1$ rituximab infusion during the first year of therapy, and also to describe characteristics of rituximabtreated patients who experienced an SIE vs those who did not.

Methods: Patients with RA enrolled in the Corrona registry and treated with rituximab were followed until their most recent Corrona registry visit, first SIE, switch to another biologic or targeted synthetic disease-modifying antirheumatic drug, or 12 months after the most recent infusion with no further retreatment whichever occurred first. The rate of SIEs was estimated in the overall population as well as in patients retreated with $\geq 1$ infusion every 12 months after rituximab initiation and in those who did not receive a repeat infusion in the first 12 months. Patient characteristics were compared between those who experienced an SIE and those who did not.

Results: A total of 1361 patients with 1821 patient-years (PY) of follow-up were included; there were 59 SIEs for a rate of 3.24 SIE/100 PYs. 637 patients $(46.8 \%)$ received $\geq 1$ rituximab retreatment during the first 12 months and 724 (53.2\%) received only the initial infusion. In the retreatment population there were 40 SIEs per 1312.8 PY for a rate $(95 \% \mathrm{Cl})$ of $3.05 / 100 \mathrm{PY}(2.18-4.15)$, and in the no retreatment population there were 19 SIEs per $508.71 \mathrm{PY}$ for a rate $(95 \% \mathrm{Cl})$ of 3.73/100 PY (2.25-5.83). The Kaplan-Meier curve depicting the occurrence of SIEs in the 2 cohorts during the first year of follow-up is shown (Figure). In the 59 patients $(4.3 \%)$ who experienced an SIE, the mean (SD) number of rituximab infusions was $1.88(1.18)$, compared with $2.07(1.70)$ in the 1302 patients $(95.7 \%)$ who did not experience an SIE. Patients who experienced an SIE vs those who did not were older (mean age [SD]: 62.9 [9.9] vs 58.1 [12.55] years), had longer disease duration (19.1 [13.1] vs 13.6 [10.4] years), were more frequently diabetic (16.9\% vs $8.3 \%)$ and more frequently had cardiovascular disease $(25.4 \%$ vs $12.8 \%)$, prior history of SIEs $(18.6 \%$ vs $5.8 \%$ ) and pulmonary disease $(10.2 \%$ vs $4.8 \%$ ). There were no differences in other clinical, demographic and medication history characteristics; steroid therapy was similar between the groups.

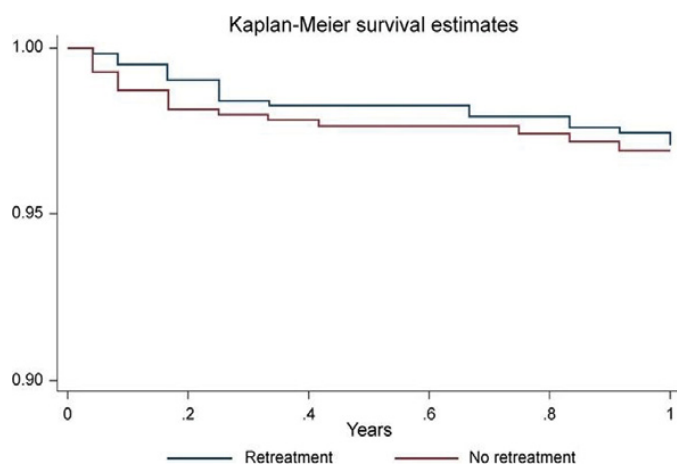

Conclusions: Retreatment with rituximab infusions was not associated with a higher rate of SIEs in this study. Patients who experienced an SIE had a higher prevalence of risk factors for infections.

References:

[1] Van Vollenhoven RF et al. J Rheumatol. 2015;42:1791-6.

Acknowledgements: This study is sponsored by Corrona, LLC. Corrona, LLC has been supported through contracted subscriptions in the last 2 years by AbbVie, Amgen, BMS, Crescendo, Eli Lilly, Genentech, GSK, Horizon Pharma USA, Janssen, Momenta Pharmaceuticals, Novartis, Pfizer, Roche and UCB. Disclosure of Interest: D. Pappas Grant/research support from: AbbVie, Consultant for: AbbVie, Employee of: Corrona, LLC, G. Reed Shareholder of: Corrona, LLC, Employee of: Corrona, LLC, S. Zlotnick Employee of: Genentech, Inc., J. Best Employee of: Genentech, Inc., R. Magner: None declared, G. Persuitte Employee of: Corrona, LLC, J. Greenberg Shareholder of: Corrona, LLC, Consultant for: Genentech; Janssen; Novartis; Pfizer; Eli Lilly, Employee of: Corrona, LLC DOI: 10.1136/annrheumdis-2017-eular.1752

\section{SAT0197 TREATMENT OUTCOMES WITH ANTI-TNF AND NON-ANTI-TNF DISEASE-MODIFYING THERAPY BY BASELINE BODY MASS INDEX}

E. Alemao $^{1}$, Z. Guo ${ }^{1}$, C. lannaccone ${ }^{2}$, M. Frits ${ }^{2}$, M. Weinblatt ${ }^{2}$, N. Shadick ${ }^{2}$ ${ }^{1}$ Bristol-Myers Squibb, Princeton; ${ }^{2}$ Brigham and Women's Hospital, Boston, United States

Background: Recent studies have indicated that being overweight or obese could reduce the effect of anti-TNF treatment in patients (pts) with RA. ${ }^{1,2}$ Other data show that certain biologic (b)DMARDs, such as abatacept, work independently of $\mathrm{BMI}^{3,4}$ Additional data on the role of BMI on treatment outcomes in clinical practice settings is required to inform clinical practice.

Objectives: To evaluate the impact of BMI on outcomes of disease activity in pts with RA treated with TNF and non-TNF agents (conventional or other bDMARDs). Methods: Pts enrolled in a tertiary care centre RA registry, established in 2003, were analysed. The registry mostly comprises pts with established RA who were evaluated semi-annually for multiple clinical patient-reported outcomes and resource utilization parameters, and annually for composite disease activity measures such as DAS28 (CRP), CDAI and SDAI. The current analysis is based on pts enrolled in the RA registry with $B M I$ values at time of enrolment. Pts were classified into groups based on BMl: normal (BMI $<25 \mathrm{~kg} / \mathrm{m}^{2}$ ), overweight (BMI $\geq 25$ to $<30 \mathrm{~kg} / \mathrm{m}^{2}$ ) and obese $\left(\mathrm{BMI} \geq 30 \mathrm{~kg} / \mathrm{m}^{2}\right.$ ). Outcomes evaluated included change from baseline in DAS28 (CRP), CDAI, SDAI and joint counts at 12 months 
from treatment exposure. Treatments were categorized into TNF and non-TNF, which included conventional DMARDs and other non-TNF biologics. Multivariate linear regression analyses were used to evaluate impact of BMI on treatment outcomes controlling for baseline covariates of age, sex, disease duration, comorbidities, baseline disease activity and serostatus. Separate models were run for the TNF and non-TNF groups.

Results: A total of $997(78 \%)$ pts in the registry had baseline BMI values and were included in the analysis. Around $37 \%(n=371)$ had TNF exposure and were included in the TNF cohort; the remainder $(63 \%$; $n=626)$ were included in the non-TNF cohort. Proportions of pts in the normal, overweight and obese groups for the TNF cohort were $45.5 \%(n=169), 27.5 \% \quad(n=102)$ and $27.0 \%(n=100)$, respectively. For the non-TNF cohort, these were $41.7 \%(n=261), 33.1 \%(n=207)$ and $25.2 \%(n=158)$, respectively. In both cohorts, pts with normal BMls were younger vs the overweight and obese BMI groups. However, obese BMI pts had higher disease activity measures at baseline (mean [SD] CDAl: 22.8 [17.8] for TNF and 24.9 [17.3] for non-TNF) vs the normal BMI pts (17.5 [15.9] for TNF and 19.9 [16.7] for non-TNF) and overweight BMI pts (20.9 [16.5] for TNF and 20.5 [15.0] for non-TNF). Adjusted mean change from baseline in disease activity in the TNF cohort was significantly reduced across all disease activity measures for the normal BMI group $(p<0.05)$, but not for the overweight and obese groups (Fig). There were significant reductions in disease activity measures for all BMl groups (all $p<0.05$ ) in the non-TNF cohort (Fig).

Figure. Association between BMI and Treatment Outcomes DAS28 (CRP), CDAI, SDAI and Joint Count
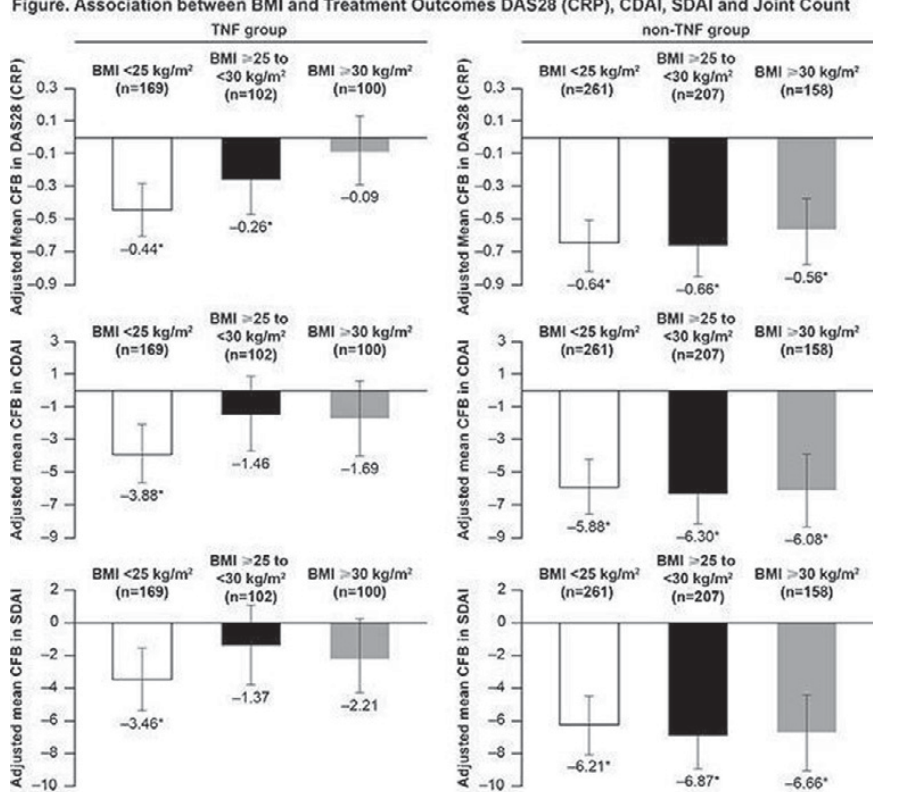

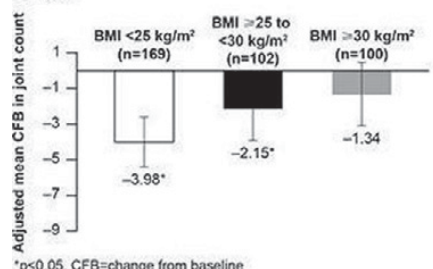

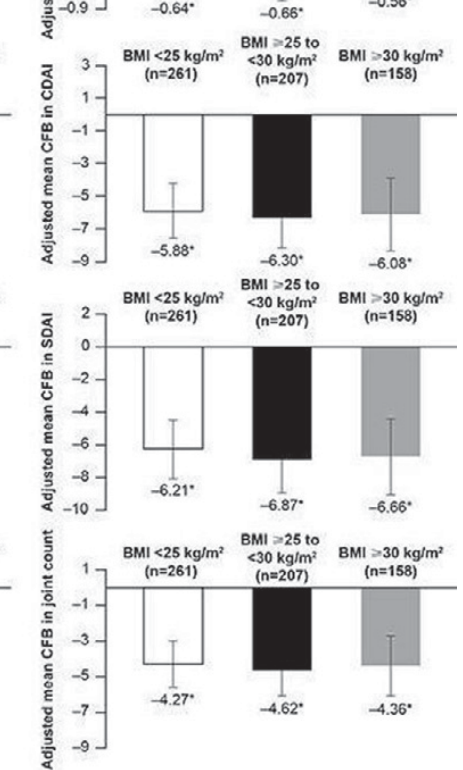

Conclusions: Independent of BMI, non-anti-TNF therapy demonstrated similar outcomes in pts with RA. However, obese and overweight pts with RA (vs normal weight) had less improvement in disease activity (as measured by DAS28 [CRP]) with anti-TNF therapy.

References:

[1] Gremese E, et al. Arthritis Care Res 2013:65:94-100.

[2] Klaasen R, et al. Arthritis Rheum 2011;63:359-64.

[3] Gardette A, et al. Ann Rheum Dis 2015;74:1041.

Disclosure of Interest: E. Alemao Shareholder of: Bristol-Myers Squibb, Employee of: Bristol-Myers Squibb, Z. Guo Shareholder of: Bristol-Myers Squibb, Employee of: Bristol-Myers Squibb, C. lannaccone: None declared, M. Frits: None declared, M. Weinblatt Grant/research support from: Amgen, Bristol-Myers Squibb, Crescendo Biosciences, UCB, DxTerity, Consultant for: Amgen, BristolMyers Squibb, Crescendo Biosciences, UCB, AbbVie, Lilly, Pfizer, Roche, N. Shadick Grant/research support from: Bristol-Myers Squibb, UCB, Mallinckrodt, Amgen, Brescendo Biosciences, Consultant for: Bristol-Myers Squibb DOI: 10.1136/annrheumdis-2017-eular.1566

\section{SAT0198 TOCILIZUMAB FOR THE MANAGEMENT OF RHEUMATOID ARTHRITIS: DISCONTINUATION DUE TO INEFFICACY AND TOXICITY - EXPERIENCE FROM A LARGE TEACHING HOSPITAL}

E. Byrne, P. Mark, S. Khalid, K.-P. Kuet, R. Kilding, K. Graves, J. Maxwell, M. Akil. Rheumatology, Sheffield Teaching Hospitals, Sheffield, United Kingdom

Background: Tocilizumab (TCZ) is a humanised anti interleukin-6 receptor antibody licensed for use for the treatment of moderate to severe Rheumatoid Arthritis (RA) as monotherapy or in combination with methotrexate (MTX).

Objectives: To describe the use of TCZ for RA in a large UK teaching centre and examine reasons for treatment discontinuation.

Methods: A retrospective case note review of all adult patients receiving TCZ either alone or in combination with DMARDS, for the treatment of RA between April 2009 and January 2017 in Sheffield, UK.

Results: 132 patients received TCZ for RA. $71 \%$ were female. $61 \%$ were CCP positive. Mean disease duration was 15.6 years (range 1.5-43). 46 (34.6\%) received TCZ as monotherapy, $55(42.1 \%)$ in combination with MTX and 31 (23.3\%) other DMARDS. $23 \%$ of patients received concomitant oral prednisolone. Median duration of TCZ treatment was 27 months across the whole cohort, and 19 months in those who discontinued treatment.

Overall $44(33 \%)$ patients discontinued TCZ; 5 due to primary and 10 secondary inefficacy, 27 patients due to adverse events ( 8 recurrent infection, 5 abnormal LFT, 4 malignancy, 3 rash, 7 other including 1 death whilst on treatment). A logistic regression model, including gender, smoking status, disease duration, DMARD use, steroid treatment and number of prior biologics was constructed to examine association with treatment discontinuation. Of these factors, disease duration $(p=0.05)$ and number of previous biologics $(p=0.09)$ were weakly associated with persistence of TCZ and in particular there was no association of concomitant DMARD or steroid treatment with discontinuation either due to lack of efficacy or adverse events. Table 1 demonstrates the proportion of patients stopping treatment, and treatment duration according to previous biologic treatment received. We have not seen any cases of infusion reaction, diverticular perforation or reactivation of tuberculosis.

Table 1. Proportion of Patients Continuing TCZ and Treatment Duration According to Previous Biologic Treatment

\begin{tabular}{lccccc}
\hline & & \multicolumn{3}{c}{ Previous Biologics Received } \\
\cline { 3 - 6 } & & 0 & 1 & 2 & 3 or more \\
\hline Continued & N (\%) & $15(83 \%)$ & $31(66 \%)$ & $24(51 \%)$ & $12(60 \%)$ \\
Discontinued & Treatment Duration (Mths) & 46 & 27 & 26 & 58 \\
& N (\%) & $3(17 \%)$ & $16(34 \%)$ & $23(49 \%)$ & $8(40 \%)$ \\
& Treatment Duration (Mths) & 4.5 & 14 & 24 & 18 \\
& Lack of Efficacy/Toxicity & $2 / 1$ & $7 / 9$ & $9 / 14$ & $3 / 5$ \\
\hline
\end{tabular}

${ }^{*}$ To date.

Conclusions: Our real world data on the use of TCZ in the treatment of adult patients with RA is consistent with clinical trial data for efficacy and safety and is similar to other biological drugs used in the treatment of RA. We have seen a relatively low rate of withdrawal due to primary and secondary treatment failure.

Disclosure of Interest: None declared

DOI: 10.1136/annrheumdis-2017-eular.5105

\section{SAT0199 SUBCUTANEOUS TOCILIZUMAB MONOTHERAPY OR COMBINED WITH A CSDMARD IN PATIENTS WITH RHEUMATOID ARTHRITIS: TOZURA, A POOLED ANALYSIS OF PHASE IV STUDIES IN 22 COUNTRIES}

E. Choy ${ }^{1}$, R. Caporali ${ }^{2}$, R. Xavier ${ }^{3}$, B. Fautrel ${ }^{4}$, R. Sanmarti ${ }^{5}$, C. Bernasconi ${ }^{6}$, A. Pethö-Schramm ${ }^{6}$. ${ }^{1}$ Cardiff University, Cardiff, United Kingdom; ${ }^{2}$ University of Pavia, Pavia, Italy; ${ }^{3}$ Universidade Federal do Rio Grande do Sul Porto Alegre, Rio Grande do Sul, Brazil; ${ }^{4}$ Pierre and Marie Curie University, Paris, France; ${ }^{5}$ Universitat de Barcelona, Barcelona, Spain; ${ }^{6}$ F. Hoffmann-La Roche AG, Basel, Switzerland

Background: Tocilizumab administered subcutaneously (TCZ-SC) has been approved for the treatment of rheumatoid arthritis (RA) both as mono- and combination therapy.

Objectives: To evaluate the efficacy and safety of TCZ-SC $162 \mathrm{mg}$ once weekly (qw) as monotherapy or in combination with conventional synthetic DMARDs (csDMARDs) over 24 weeks in adult patients (pts) with moderate to severe RA.

Methods: TOZURA is a multinational, open-label, single-arm umbrella program comprising 7 single-country and 4 regional multicountry protocols (total 22 countries). Pts enrolled were inadequate responders to DMARD, and previous biologic DMARDs were allowed in 8 of 11 protocols. Pts received TCZ-SC 162 mg qw for 24 weeks administered at the investigator's discretion as monotherapy or in combination with a csDMARD. Stable oral NSAIDs and corticosteroids (CS), $\leq 10 \mathrm{mg} /$ day prednisone or equivalent, were allowed. Efficacy and safety were evaluated at weeks 1, 2, 4 and every 4 weeks for 24 weeks (plus 8 weeks for safety). Propensity score-based matching was used for between-group tests.

Results: Of 1804 pts treated, $353(19.6 \%)$ received monotherapy (mono) and $1451(80.4 \%)$ combination therapy (combo); 349 pts (19.3\%) had received a prior biologic DMARD. Background characteristics: $81.6 \%$ female; mean age, 54.1 